\title{
A novel handmade "multi-bending endoscope system" for endoscopic submucosal dissection of difficult-to-approach superficial gastric neoplasms
}

Maintaining a good operative field is crucial when performing endoscopic submucosal dissection (ESD) for superficial gastrointestinal tumors, but it often requires high skill or special equipment depending on the location of the lesion [1-5]. Early gastric cancers are frequently detected at the lesser curvature of the gastric body, but ESD of lesions in this area may be challenging because of the difficult approach. A multi-bending endoscope is a good option for such a situation [1], but it is not widely used owing to its limited purpose and relatively high cost. We therefore developed a handmade multibending system and used it to perform ESD for 12 difficult-to-approach lesions located at the lesser curvature of the gastric body. Herein, we report the method and efficacy of the system.

The tip of the external tube (Crusher catheter, Zeon Medical, Japan) was fixed with tape about $15-20 \mathrm{~cm}$ away from the tip of a gastroscope (Olympus or Fujifilm, Tokyo, Japan) (\Fig.1). A fishing line (PE line, \#3, 40lb) was passed through the external tube, and then bound and fixed with tape at the original first bend. A second bend was created by pulling the fishing line, and fixed using a three-way stopcock according to the circumstances.

In all 12 cases, the operator could closely and tangentially approach each lesion with the tip of the endoscope using the multi-bending system ( $\triangleright$ Fig. 2 , - Video 1). Therefore, en bloc resections by ESD with an ITknife2 (Olympus) or FlushknifeBT (Fujifilm) were achieved more easily and speedily without any complications. The average resected specimen diameter and procedure times were $39.4 \mathrm{~mm}$ and 35.8 minutes, respectively.

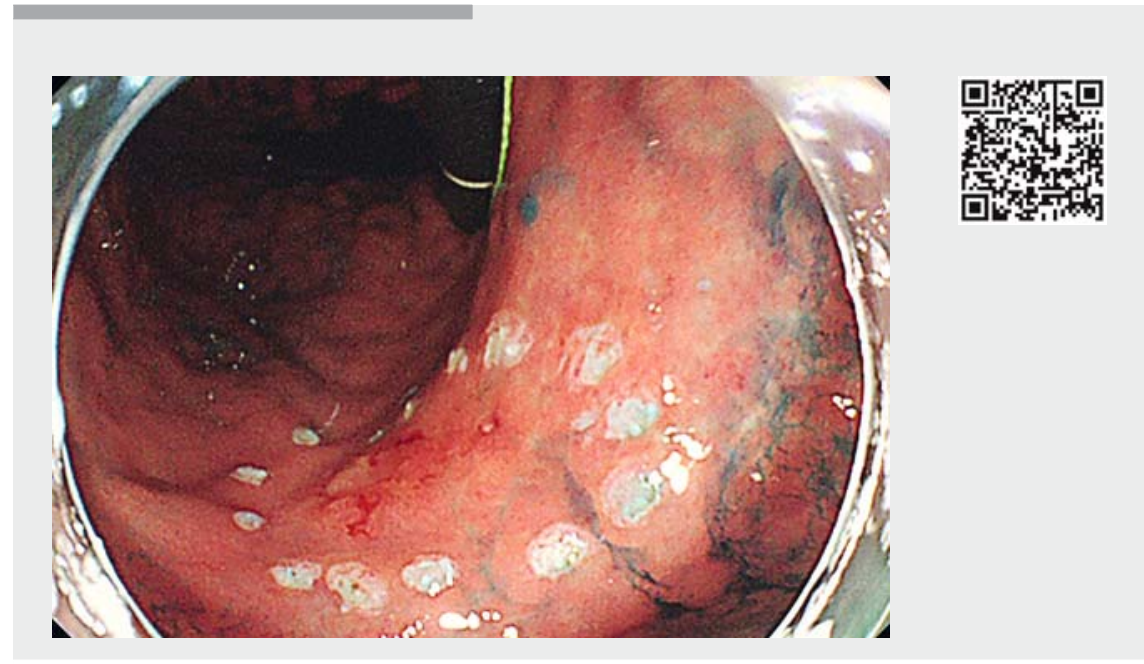

Video 1 Creation of the handmade multi-bending system and use of the device to perform endoscopic submucosal dissection of difficult-to-approach early gastric cancer at the lesser curvature of the lower gastric body.
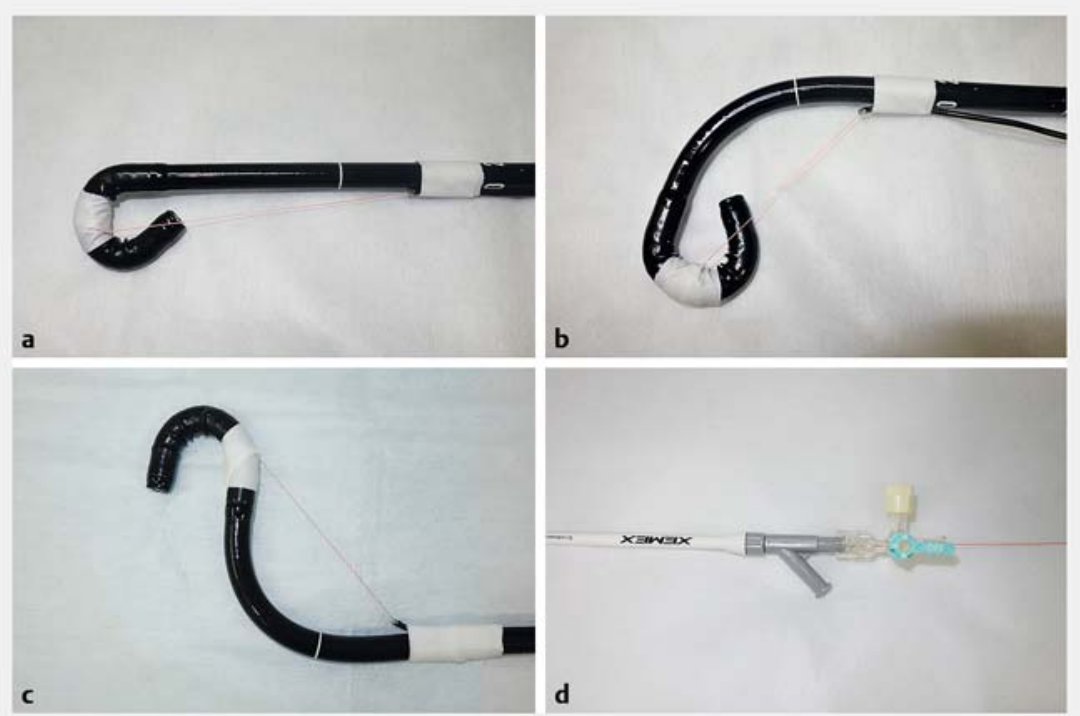

- Fig. 1 Appearance of the handmade multi-bending system. a The handmade multi-bending system before creating the second bend. $\mathbf{b}$ The second bend is created by pulling the fishing line, which is passed through the external tube. $\mathbf{c}$ The second bend can also be created on the opposite side. $\mathbf{d}$ The sheath of a Crusher catheter with a three-way stopcock is used as an external tube. The second bend can be fixed by locking the three-way stopcock. 


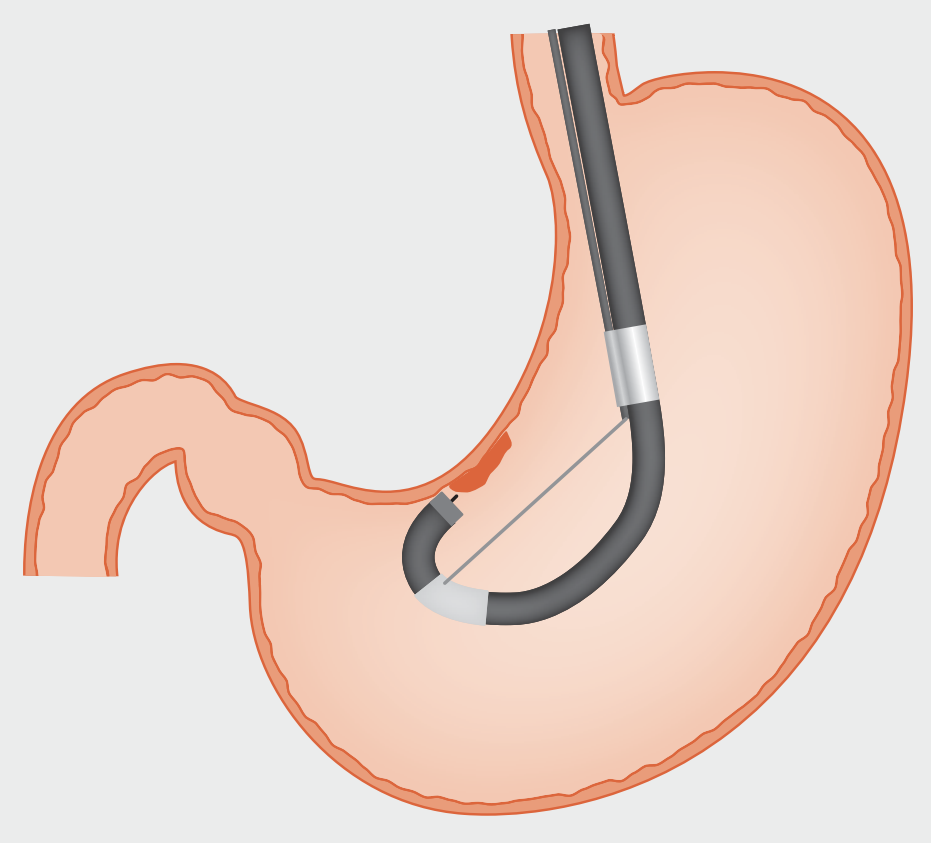

- Fig. 2 Approach to the lesion at the lesser curvature of the gastric body using the handmade multi-bending system. The lesion is approached closely and tangentially using the handmade multi-bending system.

Our handmade multi-bending system functions like a multi-bending endoscope and seems to be a very effective option for ESD of difficult-to-approach lesions located at the lesser curvature of the gastric body.

Endoscopy_UCTN_Code_TTT_1AO_2AG

Competing interests

None
The authors

Katsumi Yamamoto', Kohei Tanaka², Shiro Hayashi ${ }^{3}$, Mariko Sawamura ${ }^{1}$, Nobuyuki Tatsumi ${ }^{1}$, Tomoki Michida ${ }^{4}$, Toshifumi Ito ${ }^{1}$

1 Department of Gastroenterology, Japan Community Healthcare Organization, Osaka Hospital, Osaka, Japan

2 Department of Internal Medicine, Tanaka Naika lin, Osaka, Japan

3 Department of Gastroenterology, Toyonaka Municipal Hospital, Osaka, Japan

4 Department of Gastroenterology, Saitama Medical Center, Saitama, Japan

\section{Corresponding author}

\section{Katsumi Yamamoto, MD, PhD}

Department of Gastroenterology, Japan Community Healthcare Organization (JCHO) Osaka Hospital, 4-2-78 Fukushima, Fukushima-ku, Osaka 553-0003, Japan Fax: +81-6-64458900

yamamoto-kts@umin.ac.jp

\section{References}

[1] Yahagi N, Fujishiro M, Kakushima $\mathrm{N}$ et al. Clinical evaluation of the multibending scope in various endoscope procedures of the upper GI tract. Dig Endosc 2005; 17: (Suppl. 01): S94-S96

[2] Kawamura M, Seike H, Kikuchi T et al. Endoscopic submucosal dissection for gastric neoplasms by using a novel attachment device - a one-sided, expandable balloon. Gastrointest Endosc 2011; 74: 415-418

[3] Yamamoto K, Hayashi S, Nishida T et al. Effective use of the "clip-flap method" for a difficult-to-approach lesion in endoscopic submucosal dissection of a superficial gastric tumor. Endoscopy 2015; 47: E318 - E319

[4] Suzuki S, Gotoda T, Kobayashi Y et al. Usefulness of a traction method using dental floss and a hemoclip for gastric endoscopic submucosal dissection: a propensity score matching analysis (with videos). Gastrointest Endosc 2016; 83: 337 - 346

[5] Imaeda H, Hosoe N, Kashiwagi K et al. Advanced endoscopic submucosal dissection with traction. World J Gastrointest Endosc 2014: 6: 286-295

\section{Bibliography}

DOI https://doi.org/10.1055/a-0820-1824

Published online: 7.2.2019

Endoscopy 2019; 51: E83-E84

(c) Georg Thieme Verlag KG

Stuttgart · New York

ISSN 0013-726X

\section{ENDOSCOPY E-VIDEOS \\ https://eref.thieme.de/e-videos}

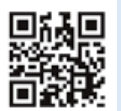

Endoscopy E-Videos is a free access online section, reporting on interesting cases and new

techniques in gastroenterological endoscopy. All papers include a high quality video and all contributions are freely accessible online.

This section has its own submission website at

https://mc.manuscriptcentral.com/e-videos 